\title{
Dorsal Lumbar Disc Migrations with Lateral and Ventral Epidural Extension on Axial MRI: A Case Series and Review of the Literature
}

\author{
(D) M.M. Zarrabian, (DF.E. Diehn, (D)A.L. Kotsenas, DJ.T. Wald, (DE. Yu, and (D)A. Nassr
}

\begin{abstract}
SUMMARY: Dorsal epidural migration of lumbar disc extrusion is rare and commonly misdiagnosed. Our purpose was to retrospectively analyze soft-tissue abnormalities on axial MR imaging in both the ventral and lateral epidural space in such dorsal epidural migrations. The presence of each component required complete concordance by 3 independent neuroradiologist readers. In a case series ( $n=6$ ) of surgically proved dorsal lumbar disc migrations, in which the radiologist's favored prospective diagnosis had not been correct, each case demonstrated epidural soft-tissue abnormality that had components both laterally and ventrally, abutting the parent disc. Similarly, in previously published cases for which axial MR imaging was available, the lateral component was demonstrated in 23/24 cases (96\%). Ventral abutment of the parent disc was evident, in addition, in 17/18 cases (94\%) with available disc-level axial images. Both ventral and lateral epidural soft-tissue abnormalities are typically present in dorsal lumbar disc herniations and may help radiologists suggest this rare diagnosis in appropriate cases.
\end{abstract}

$\mathbf{P}$ er the second version of lumbar disc nomenclature derived by multisociety task forces, a disc extrusion is defined as a disc herniation that is displaced "beyond the outer annulus of the disc material with any distance between its edges greater than the distance between the edges of the base..."; the term "migration" refers to "displacement of disc material away from the site of extrusion...regardless of continuity with the disc...in either the sagittal or axial plane."1 Lumbar disc extrusions are common, with disc material typically migrating superiorly, inferiorly, or laterally. ${ }^{2}$ Migration into the dorsal epidural space (Fig 1), however, is rare. This was first described by Lombardi ${ }^{3}$ in 1973 as a "posterior rotation of the annulus fibrosis." Posterior migration of the disc is thought to be anatomically inhibited by the posterior longitudinal ligament and the peridural membrane, midline septum, epidural fat/venous plexus, dura, and nerve root. ${ }^{4-6}$

Dorsal disc migrations are uncommon, with fewer than 100 reported cases, and a diagnostic challenge for several other reasons. ${ }^{7,8}$ They can present with atypical clinical features, including a relatively

Received March 17, 2016; accepted after revision May 15.

From the Departments of Orthopedic Surgery (M.M.Z., A.N.) and Radiology (F.E.D., A.L.K., J.T.W.), Division of Neuroradiology, Mayo Clinic, Rochester, Minnesota; and Department of Orthopaedics (E.Y.), Division of Spine, Ohio State University, Com prehensive Spine Center, Columbus, Ohio.

Please address correspondence to Felix E. Diehn, MD, Division of Neuroradiology, Department of Radiology, Mayo Clinic, 200 lst St SW, Rochester, MN 55905;

e-mail: diehn.felix@mayo.edu

http://dx.doi.org/10.3174/ajnr.A4875 high prevalence (55\%) of cauda equina syndrome. ${ }^{7}$ In addition, their MR imaging findings overlap much more common differential considerations, such as synovial cyst and epidural abscess. Neither signal characteristics nor enhancement pattern of dorsal disc migrations allow a confident diagnosis on MR imaging. Previous reviews of the literature have shown that standard MR imaging features such as T1 and T2 signal characteristics are variable and nonspecific. ${ }^{5,7,9}$ Like other disc herniations, the gadolinium-enhancement pattern is typically peripheral, ${ }^{6}$ but this is also nonspecific, and intravenous contrast is often not administered in routine cases.

Morphologically, the phenomenon of dorsal epidural disc migration has often been referred to as a "posterior sequestered disc fragment" in prior articles. However, we have anecdotally observed, in our clinical practice, that in at least some cases of dorsal disc migration, the abnormal epidural soft tissue on MR imaging is typically not purely located in the dorsal epidural space. Rather, as noted in a prior single case report, ${ }^{6}$ the abnormality contacts the parent disc in the ventral epidural space and from there asymmetrically involves the lateral epidural space to reach a posterior location. The purpose of the present clinical report was to analyze this morphology on axial MR imaging in dorsal lumbar disc herniations, both in a retrospective case series and in images of previously published cases.

\section{Case Series}

Institutional review board approval with waived consent was obtained for this Health Insurance Portability and Accountability Act-compliant retrospective clinical report. The study took place 
at Mayo Clinic in Rochester, Minnesota. Between 2006 and 2015, 6 patients from our spine surgery practice with surgically and pathologically proved diagnoses of dorsal lumbar disc migration were identified through a search of the electronic medical record, including radiologic, surgical, and pathologic data bases. The relevant clinical, imaging, and surgical features were reviewed. We searched PubMed for published reports of dorsal lumbar disc herniation, during 2000-2015. Search terms included "dorsal/ posterior epidural disc/disk herniation," "extrusion," "migration," and "sequestration." Relevant references from identified articles were reviewed. For all cases (series and literature), a staff

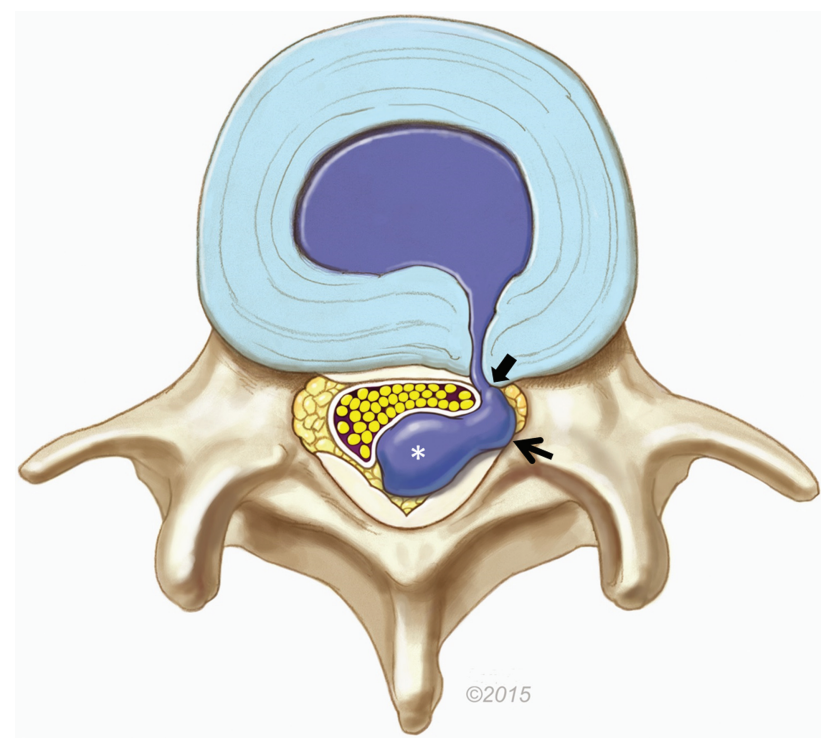

FIG 1. Illustration of a dorsal lumbar disc herniation. The bulk of the herniated disc material is located in the dorsal epidural space (asterisk), causing mass effect on the thecal sac and cauda equina. However, a lateral epidural component is also present (arrow). In this example, disc material extends into the ventrolateral epidural space directly to a rent in the annulus, contiguous with the parent disc (block arrow). On MR imaging, the soft tissue ventrally/laterally can represent disc material and/or granulation tissue. Reproduced with permission from the Mayo Foundation for Medical Education and Research. neuroradiologist with American Board of Radiology certification and a Certificate of Added Qualification in neuroradiology (F.E.D., with 6 years of postfellowship experience) recorded the cases that had available axial MR images of sufficient quality to evaluate 2 specific morphologic features: 1) epidural soft tissue wrapping laterally around the thecal sac from ventrolateral to dorsolateral/dorsal, and 2) apparent abutment with the parent disc in the ventral epidural space at disc-level axial images, when available (Fig 1). These 2 features on axial images only were evaluated at an electronic workstation independently by 3 staff neuroradiologists with the same qualifications (F.E.D., A.L.K., and J.T.W., with 6,17 , and 20 years of postfellowship experience, respectively). The features were considered present only if all 3 neuroradiologists graded them as evident. Because most cases did not include postcontrast imaging, no attempt was made to discriminate whether the ventral/lateral epidural soft tissue, if present, represented either actual disc material and/or granulation tissue extending to the dorsally migrated disc material.

The clinical and relevant MR imaging features of the 6 cases are shown in the Table. The interpreting radiologist's clinical report was available in 5 cases ( 1 outside MR imaging was not formally interpreted; each interpreting radiologist had American Board of Radiology certification and a Certificate of Added Qualification in neuroradiology); in no case was the dorsal disc herniation the favored diagnosis (Table). On independent analysis by all 3 reviewing neuroradiologists, all 6 of these dorsally migrated disc herniations demonstrated the epidural soft-tissue abnormality both wrapping laterally around the thecal sac and abutting the parent disc. In case 1, MR imaging (Fig 2) demonstrated a $3.5-\mathrm{cm}$ peripherally enhancing (Fig $2 C,-F$ ) left dorsal epidural mass, extending from the L4 to the lower L5 body levels. At the operation, a large, flat, adherent, and firm left dorsal mass of disc material (pathologically confirmed) was resected (Fig 3). This tracked from L3 to L5, enveloping the L5 nerve circumferentially. The patient obtained relief of the leg pain and was discharged on postoperative day 3.

In case 2, MR imaging (Fig 4) demonstrated a 1.9-cm dorsal epidural mass at L3-4, contributing to severe spinal stenosis. The

Clinical and MRI features of 5 patients with dorsal epidural disc herniations

\begin{tabular}{|c|c|c|c|c|c|c|}
\hline $\begin{array}{l}\text { Case } \\
\text { No./Age } \\
\text { (yr)/Sex }\end{array}$ & Symptoms & Side/Level & $\begin{array}{l}\text { Lateral Soft } \\
\text { Tissue }\end{array}$ & $\begin{array}{l}\text { Ventral Soft } \\
\text { Tissue, } \\
\text { Abutting } \\
\text { Disc }\end{array}$ & $\begin{array}{l}\text { Gadolinium } \\
\text { Enhancement }\end{array}$ & $\begin{array}{l}\text { Radiologist's } \\
\text { Favored } \\
\text { Diagnosis }\end{array}$ \\
\hline $1 / 48 / M$ & $\begin{array}{l}\text { 3-Week back pain, radiating to right lower } \\
\text { extremity, paresthesias on dorsum of right } \\
\text { foot, urinary hesitancy }\end{array}$ & Left/L4-5 & Yes & Yes & Peripheral & Epidural abscess \\
\hline $2 / 77 / M$ & $\begin{array}{l}\text { 4-Month low back pain, intermittent radiation } \\
\text { into right }>\text { left lower extremities, } \\
\text { weakness; acutely unable to ambulate }\end{array}$ & Right/L3-4 & Yes & Yes & NA & Epidural hematoma \\
\hline $3 / 69 / \mathrm{M}$ & $\begin{array}{l}\text { 2-Week low back pain radiating into thighs, } \\
\text { progressive right lower extremity weakness }\end{array}$ & Left/L2-3 & Yes & Yes & NA & Synovial cyst \\
\hline 4/61/M & $\begin{array}{l}\text { 5-Day low back pain, 2-day progressive right } \\
\text { lower extremity weakness }\end{array}$ & Left/L3-4 & Yes & Yes & NA & Epidural hematoma \\
\hline $5 / 35 / M$ & $\begin{array}{l}\text { 1-Week back and bilateral lower extremity } \\
\text { pain, weakness }\end{array}$ & Left/L4-5 & Yes & Yes & Peripheral & NA \\
\hline $6^{\mathrm{a}} / 60 / \mathrm{M}$ & $\begin{array}{l}\text { 3-Week progressive severe right lower } \\
\text { extremity radicular pain, resulting in } \\
\text { hospital admission for pain control }\end{array}$ & Right/L4-5 & Yes & Yes & Peripheral & Epidural abscess \\
\hline
\end{tabular}

Note:-NA indicates not applicable.

${ }^{a}$ Images from case 6 appear in Diehn et al. ${ }^{8}$ 


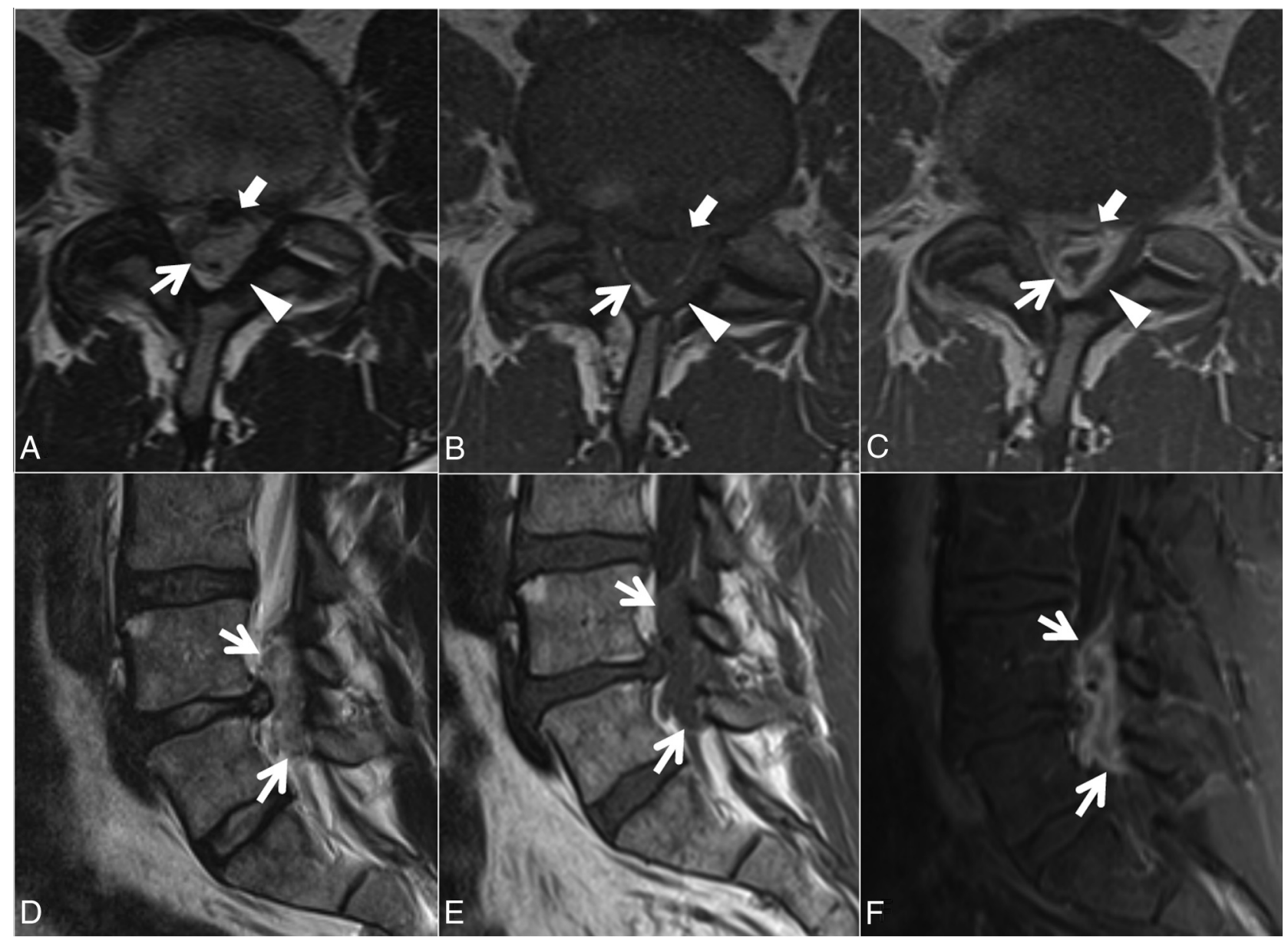

FIG 2. Case 1. A 48-year-old man with 3 weeks of back pain radiating to the right lower extremity and paresthesias on the dorsum of the right foot. Axial T2- $(A)$, T- $(B)$, and postcontrast T1-weighted $(C)$ and sagittal T2- $(D)$, T- $(E)$, and postcontrast fat-suppressed Th-weighted $(F)$ images. A heterogeneous predominantly $\Pi$-isointense, T2-hyperintense $3.5-\mathrm{cm}$ maximal dimension mass (white arrows, $A-F$ ) in the dorsal and left lateral epidural fat partially abutting the left ligamentum flavum (arrowheads, A-C) contributes to severe L4-5 spinal stenosis, with rightward displacement and effacement of the thecal sac. There is no definite connection to the left L4-5 facet joint. The left lateral epidural fat is effaced, and the dorsal mass is contiguous with the dorsal margin of the $L 4-5$ disc (white block arrow in $A-C$ ). The mass peripherally enhances ( $C$ and $F$ ). The radiologist's interpretation favored epidural abscess. At the operation, the dorsal disc herniation was an inflammatory-appearing mass with considerable adhesion to the undersurface of the lamina. Also contributing to the $L 4-5$ stenosis are a disc protrusion and ligamentum flavum redundancy.

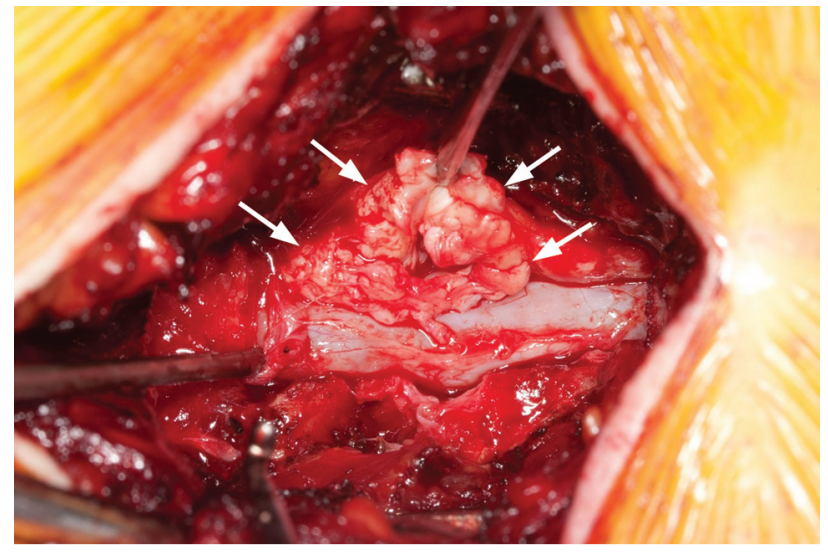

FIG 3. Case 1. Intraoperative photo after an L4-5 laminectomy demonstrates a left-sided mass (arrows) pathologically proved to be disc material.

radiologist's differential diagnosis favored focal epidural hematoma and included dorsal disc migration, a synovial cyst, or sequela of a recent epidural injection. At the operation, a $2-\mathrm{cm}$ dorsal disc fragment (pathologically confirmed) adherent to the dura at L3-4 was resected. This disc fragment was followed laterally to the right aspect of the L3-4 disc, where a rent in the annulus was detected in the foraminal zone. The patient was discharged on postoperative day 2 with noted improvement in pain, ambulation, and strength.

In case 3, MR imaging (Fig 5) showed severe central canal stenosis due to spondylotic changes and developmental narrowing, greatest at L2-3 and L4-5. At L2-3, a 2.0-cm left dorsallateral epidural mass contributed to the stenosis. At the operation, left L2-3 disc material (pathologically confirmed) was visualized dorsally, resected, and followed to the ventral aspect of the disc. No rent in the annular fibers was visualized. Postoperatively, the patient had resolution of pain and recovery of motor deficits. He was discharged on postoperative day 3.

In case 4, MR imaging (Fig 6) demonstrated spondylotic changes causing multilevel severe central stenosis from L1 to S1, most notable at L3-4 due to a 1.3-cm left dorsal-lateral epidural mass. At the operation, an L3-4 left disc fragment (pathologically confirmed) was resected. This fragment had a tail that wrapped 


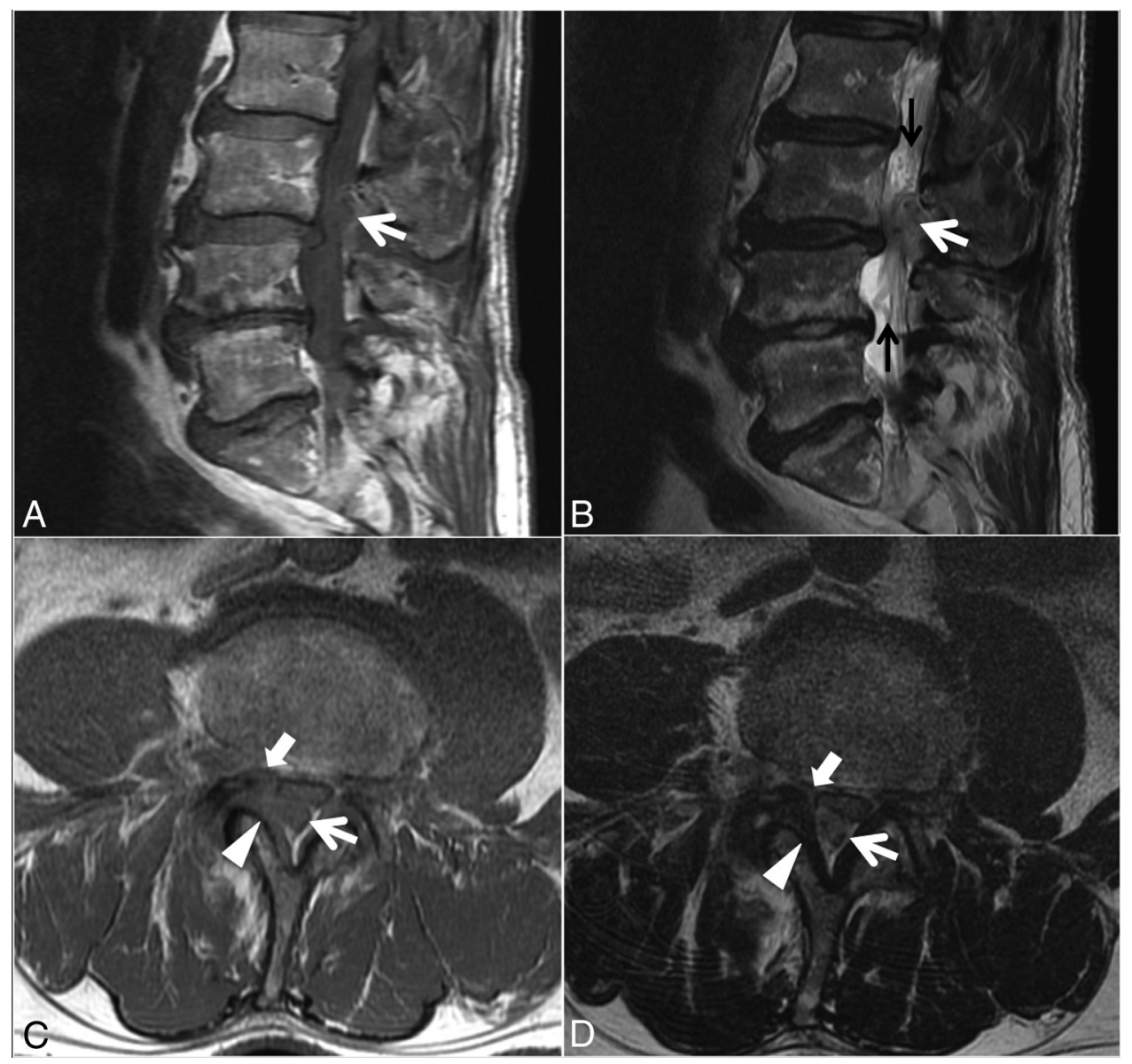

FIG 4. Case 2. A 77-year-old man with 4 months of low back pain and intermittent radiation into the right-more-than-left lower extremities, as well as weakness and an acute inability to ambulate. Sagittal T1- $(A)$ and T2-weighted $(B)$ and L3 inferior endplate-level axial T1- (C) and T2-weighted $(D)$ images. A heterogeneous predominantly T1-isointense, mildly T2-hyperintense, 1.9-cm maximal-dimension mass (white arrows, $A-D$ ) in the dorsal and right lateral epidural fat abutting the right ligamentum flavum (arrowheads, C-D) contributes to severe L3-4 spinal stenosis, with leftward displacement and effacement of the thecal sac. There is no definite connection to the right L3-4 facet joint. The right lateral epidural fat is effaced, and the dorsal mass is contiguous with the dorsal margin of the L3-4 disc (white block arrow in C-D). Differential considerations in the radiologist's interpretation included focal epidural hematoma (particularly given the acute clinical presentation), dorsal migration of a disc fragment, an unusual-appearing synovial cyst or other degenerative cyst, and sequela of the recent epidural injection. At the operation, the dorsal disc herniation was indeed traced back to a large annular defect at the right lateral margin of the L3-4 disc. Also contributing to the L3-4 stenosis are slight retrolisthesis of $\mathrm{L} 3$ on $\mathrm{L} 4$, a disc bulge, and ligamentum flavum redundancy. Tortuosity of the cauda equina (black arrows, $B$ ) is compatible with the high-grade stenosis. An L1-2 left subarticular disc extrusion causing advanced lateral recess narrowing is also present at the superior aspect of the sagittal images $(A$ and $B)$.

toward the disc at this level. This was followed ventrally, with no additional fragment identified. The patient was discharged on postoperative day 2 with resolution of pain and ongoing weakness in the ankle dorsiflexors of his right foot.

In case 5, MR imaging (not shown) demonstrated severe central stenosis at $L 4-5$ due primarily to a $2.9-\mathrm{cm}$ peripherally enhancing left dorsal epidural mass, extending from the mid-L4 to the upper L5 body levels. At surgery, a large left dorsal mass of disc material (pathologically confirmed) compressing the thecal sac was resected. This was traced back to an L4-5 annular defect. At a 6-week follow-up, the patient described marked improvement in back and leg symptoms and demonstrated considerably greater lower extremity strength.

In case 6, MR imaging (not shown; images from this case are included in a pictorial review of unusual manifestations of disc pathologic conditions ${ }^{8}$ ) demonstrated severe spinal stenosis at L4-5 due primarily to a $4.0-\mathrm{cm}$ peripherally enhancing large right ventrolateral-through-foraminal and dorsal epidural soft-tissue mass, extending from L4-5 to L3-4. At the operation, densely fibrous disc material (pathologically confirmed) was resected, with complete decompression of the thecal sac and right foramen. The patient was discharged on postoperative day 2 and was completely pain-free at a 3-week follow-up.

\section{Analysis of Images from Published Cases}

In addition to our 6 cases, 52 cases from 22 articles on dorsallumbar disc herniation dating back to 2000 were identified. ${ }^{5-7,9-27}$ Note that a unique case describing sequestered fragments migrating into facet joints was not included among these 52 cases and was excluded. ${ }^{28}$ Among the 52 cases, MR images were available in 29 cases (56\%) from 19 articles. - $^{5,9-15,17-19,21,23-27}$ One case was eliminated due to poor image quality (case 1 from Sengoz et $\mathrm{al}^{11}$ ). At least 1 axial MR image was included in 24 of the remaining 28 cases $(86 \%)$. Thirteen of the published cases included a single axial image, and 11 had at least 2 axial images, with 8 of the latter containing $>1 \mathrm{MR}$ imaging sequence type. 


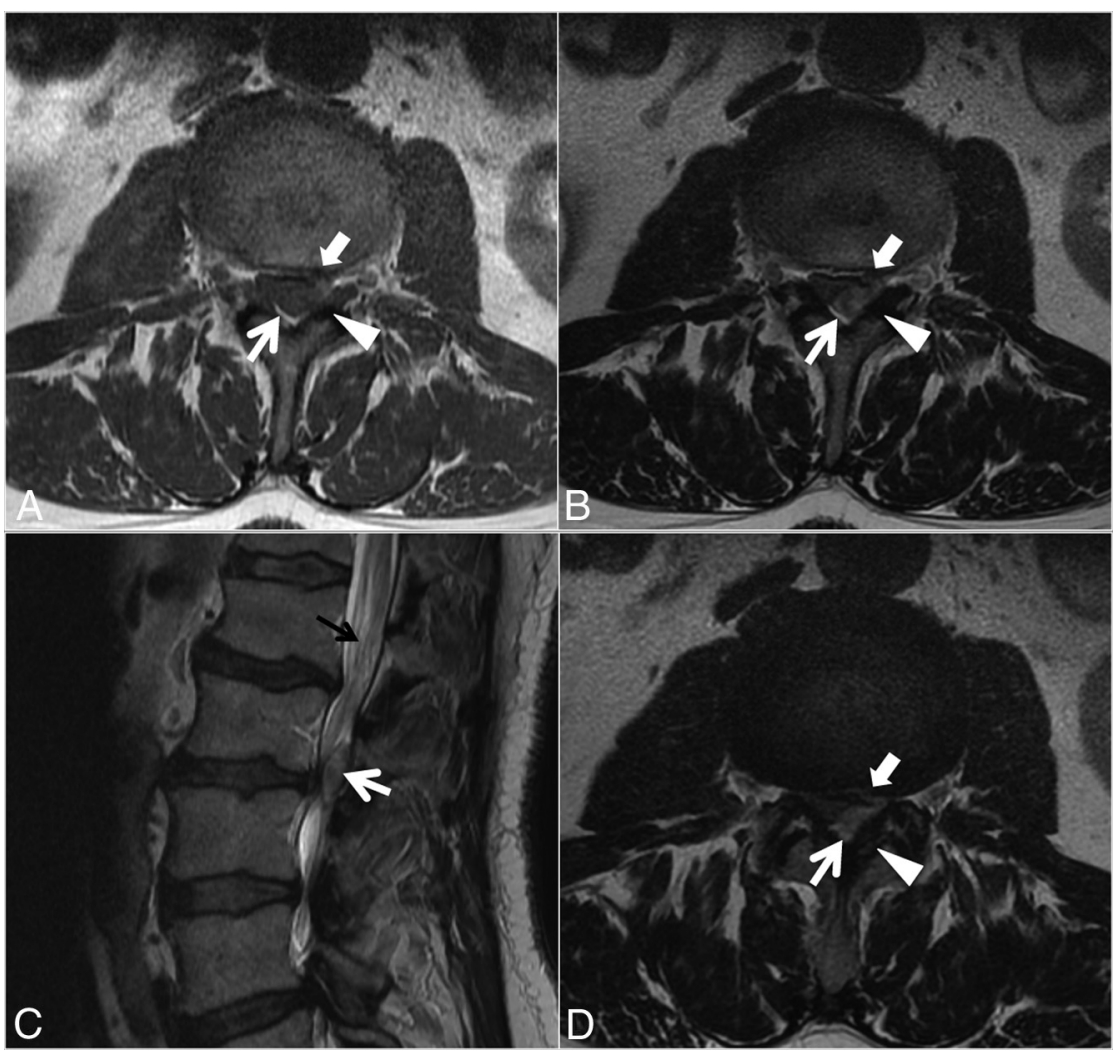

FIG 5. Case 3. A 69-year-old man with 2 weeks of low back pain radiating into the thighs and progressive right lower extremity weakness. Axial T1- $(A)$ and T2-weighted ( $B$ and $D ; D$ is 1 section below $A$ and $B$ ) and sagittal T2-weighted $(C)$ images. A heterogeneous predominantly T1-isointense, T2-hyperintense, $2.0-\mathrm{cm}$ maximal-dimension mass (white arrows, $A-D$ ) in the dorsal and left lateral epidural fat abutting the left ligamentum flavum (arrowheads, $A, B$, and $D$ ) contributes to severe L2-3 spinal stenosis, with rightward displacement and effacement of the thecal sac. There is no definite connection to the left L2-3 facet joint. The left lateral epidural fat is effaced, and the dorsal mass is contiguous with the dorsal margin of the L2-3 disc (white block arrows in $A, B$, and $D$, best seen in $D$ ). The radiologist's diagnosis was a synovial cyst. At surgery, the dorsal disc herniation was traced back to the ventral aspect of the canal, and the disc was probed without other fragments identified. Also contributing to the L2-3 stenosis are a developmentally narrow canal, a disc bulge, and ligamentum flavum redundancy. Mild tortuosity of the cauda equina (black arrow, C) is compatible with the high-grade stenosis.

Twenty-three of these 24 (96\%) published dorsally migrated disc herniations had at least 1 axial MR image showing an epidural softtissue abnormality wrapping laterally around the thecal sac, as independently noted by electronic review by all 3 aforementioned reviewing neuroradiologists (F.E.D., A.L.K., and J.T.W.). One case from the literature without consensus had a disc herniation localized to the median dorsal epidural space by the authors (their case 3 in their Fig 1A). ${ }^{10}$ When disc level axial images were available ( 18 cases from 15 articles), ${ }^{5-7,9,10,12-14,18,19,21,24-27} 17$ (94\%) demonstrated the epidural soft-tissue abnormality abutting the parent disc, as independently noted by all 3 reviewing neuroradiologists. For the 1 case from the literature without consensus for this morphologic feature, 2 of the 3 readers graded it present. ${ }^{24}$ In these 17 cases with abutment of the parent disc, the lateral epidural soft-tissue abnormality was also present.

\section{DISCUSSION}

The current clinical report shows that in both a small case series and a larger series of previously published cases of dorsal lumbar disc herniation, 2 morphologic features on axial MR imaging are seen in most (>90\%) cases: 1 ) asymmetric epidural soft tissue lateral to the thecal sac, and 2) on disclevel axial images, epidural soft tissue ventrally, abutting the parent disc. Indeed, the lesion typically spans from ventral/ventrolateral to dorsolateral/ dorsal, rather than being purely dorsal (such as in Figs $2 A,-C$; $4 C,-D ; 5 B,-D$; and $6 A,-B$, and $-D)$. These findings may help radiologists to more confidently suggest this relatively rare phenomenon in appropriate cases of a dorsolateraldorsal epidural soft-tissue lesion.

Although the lateral-ventrolateral epidural component may seem intuitive, it is not widely recognized. This scenario is suggested by several of the reviewed reference articles not actually stating the side of the dorsal disc herniation, simply referring to it as posterior. ${ }^{11,12,19,25,27}$ Lack of radiologists' confidence in diagnosing dorsal disc herniation, even by fellowship-trained neuroradiologists as seen in our series, is further evidence for the lack of awareness of the axial morphology we describe herein. As for the apparent contact with the parent disc, it is often not possible to distinguish whether this represents disc material remaining in contiguity or granulation tissue between sequestered material and the parent disc, particularly if postcontrast MR imaging has not been performed. Chen et $\mathrm{al}^{6}$ described this phenomenon on postgadolinium imaging in their case report of a dorsally migrated disc fragment. They noted, "A tractlike structure with enhancement from the site of the ruptured disk to the posterior epidural space was identified, suggesting the route of the sequestrated disk migration." On the basis of histopathology and existing literature, these authors attributed the contrast enhancement to granulation tissue ("increased vascularized epidural tissue wrapping the disk contents").

Suggesting the diagnosis on MR imaging is important because the frequently atypical clinical presentation of dorsal disc herniations can render the diagnosis difficult. Atypical features seen in these types of herniation include a relatively short duration of symptoms, often acute, as seen, for instance, in cases 4 and 5 of our series. Although it was not seen in our patients, there is a high occurrence of cauda equina syndrome ${ }^{7}$ compared with more typical ventral herniations. ${ }^{29,30}$ Moreover, a number of more common entities with different management approaches to surgical resection are in the differential diagnoses on MR imaging. Dorsal disc herniations are often mistaken for nondiscal lesions, such as abscess, hematoma, synovial cyst, or neoplasm on MR imaging. ${ }^{6,28}$ In our series, the interpreting radiologist favored epidural 


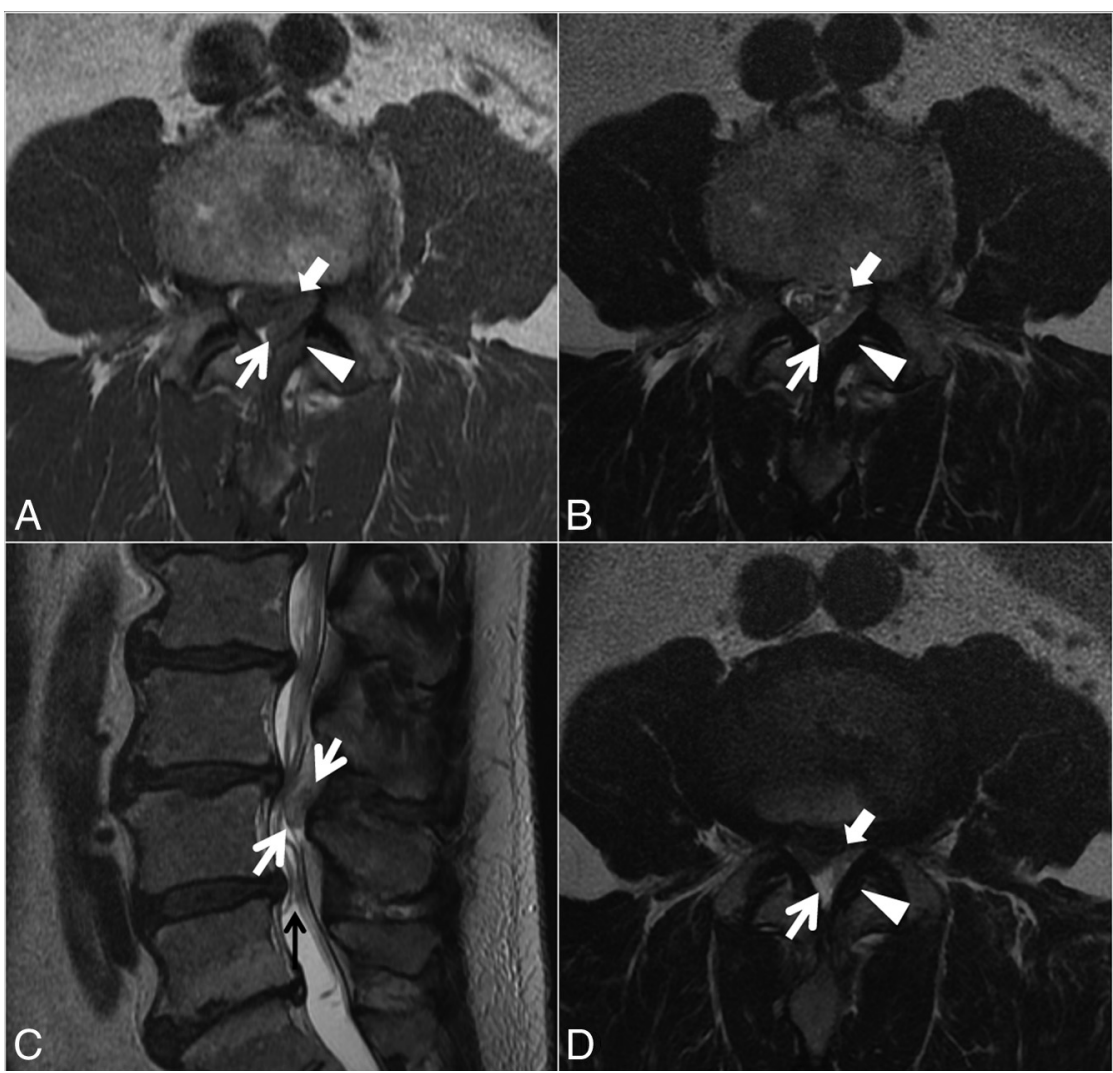

FIG 6. Case 4. A 61-year-old man with 5 days of low back pain and 2 days of progressive right lower extremity weakness. Axial T1- $(A)$ and T2-weighted ( $B$ and $D ; D$ is 1 section above $A$ and $B$ ) and sagittal T2-weighted $(C)$ images. A heterogeneous predominantly T1-isointense, mildly T2-hypointense, 1.3-cm maximal-dimension mass (white arrows, $A-D$ ) in the dorsal and left lateral epidural fat abutting the left ligamentum flavum (arrowheads, $A, B$, and $D$ ) contributes to severe L3-4 spinal stenosis, with rightward displacement and effacement of the thecal sac. There is no definite connection to the left L3-4 facet joint. The left lateral epidural fat is effaced, and the dorsal mass is contiguous with the dorsal margin of the L3-4 disc (white block arrows in $A, B$, and $D$, best seen in $D$ ). The radiologist's favored diagnosis was a small epidural hematoma, with differential considerations of a sequestered disc fragment or degenerative facet-related lesion. At the operation, the dorsal disc herniation was followed back to the ventral aspect of the canal and no other fragments were identified. Also contributing to the L3-4 stenosis are a disc bulge and ligamentum flavum redundancy. Mild tortuosity of the cauda equina (black arrow, $C$ ) is compatible with the high-grade stenosis.

hematoma in 2 cases, epidural abscess in 2, and synovial cyst in 1. Indeed, the MR imaging features of these differential considerations have considerable overlap.

Disc herniations are usually isointense on T1-weighted imaging and often are hyperintense on T2-weighted imaging, but these features are variable and nonspecific. ${ }^{5,7,9}$ In addition, they often show a variable degree of rim enhancement with gadolinium, depending on the degree of vascularity and granulation tissue formation, which also is nonspecific. ${ }^{5,9}$ Dorsal epidural disc migrations are typically treated with surgery. Epidural abscesses are typically isointense or hypointense on T1; hyperintense on T2; typically with a rim pattern of enhancement; often having signal changes at the adjacent infected osseous spinal column/disc; and having associated inflammatory changes in the adjacent paraspinal regions. ${ }^{31}$ Treatment options include systemic antibiotics, percutaneous aspiration/drainage, or an operation. Hematomas have variable signal intensities due to the heterogeneous nature and age of blood products; they may be hyperintense on T1 and may show ring enhancement during the resolution phase. ${ }^{32}$ De- pending on the clinical status of the patient, hematomas may be observed rather than evacuated. Imaging features of synovial cysts depend on the content, but they are usually adjacent to degenerative facets and often have a visible connection to them, which helps in their identification. However, dorsal disc herniations may also abut the ligamentum flavum, as in our series. Synovial cysts often have a rim of T2-hypointensity and may peripherally enhance. ${ }^{33}$ Synovial cysts may be observed, treated percutaneously, or resected surgically. Solid enhancement can be a clue for a neoplasm, but gadolinium is often not routinely administered for typical lumbar spine MR imaging indications.

Limitations of our clinical report include its retrospective nature. The supplementation of our case series with a separate analysis of published images is not ideal but allows evaluation (albeit imperfect) of considerably more cases of a rare condition. Because our design was based on anecdotal observation, we may have had an expectation bias while reviewing the images. However, the analysis was conducted independently by 3 different board-certified neuroradiologists, with complete agreement needed for the findings to be considered present. Our clinical report does not allow further characterization of how often the ventrolateral abnormal soft tissue represents granulation tissue versus contiguous disc material from the ventral to the dorsal epidural space. We did not conduct a formal analysis of the image quality of the published cases. We acknowledge that other entities on the differential diagnosis described above could (especially if large) have soft-tissue abnormalities present from the ventral-through-dorsal epidural space; thus, this morphology does remain a nonspecific finding. We did not seek to directly compare our series of dorsal disc herniations with a series of epidural hematomas, abscesses, or synovial cysts; thus, the reviewing radiologists were not blinded to the diagnosis of dorsal disc herniation for this clinical report.

In summary, rarity, atypical clinical presentation, and nonspecific MR imaging features cause difficulty in the diagnosis of dorsal lumbar disc herniation. Ventral and lateral epidural soft-tissue abnormalities are typically present on axial MR images and may help radiologists suggest this uncommon diagnosis in appropriate cases or at least include it in the differential diagnosis.

\section{ACKNOWLEDGMENTS}

The authors thank Sonia Watson, PhD, and Andrea Moran for assistance with manuscript preparation and submission. 
Disclosures: Elizabeth Yu-UNRELATED: Travel/Accommodations/Meeting Expenses Unrelated to Activities Listed: Depuy Synthes (Minimally Invasive Surgery Summit meeting); Other: practical reviews by Oakstone Publishing, Comments: summary of medical journal articles for Continuing Medical Education credit. Ahmad Nassr-UNRELATED: Grants/Grants Pending: Pfizer*; Payment for Lectures (including service on Speakers Bureaus): Magnifi Group; Stock/Stock Options: diversified mutual funds as part of retirement.* *Money paid to the institution.

\section{REFERENCES}

1. Fardon DF, Williams AL, Dohring EJ, et al. Lumbar disc nomenclature: version 2.0-recommendations of the combined task forces of the North American Spine Society, the American Society of Spine Radiology and the American Society of Neuroradiology. Spine J 2014;14:2525-45 CrossRef Medline

2. Bonaroti EA, Welch WC. Posterior epidural migration of an extruded lumbar disc fragment causing cauda equina syndrome: clinical and magnetic resonance imaging evaluation. Spine (Phila $\mathrm{Pa}$ 1976) 1998;23:378-81 CrossRef Medline

3. Lombardi V. Lumbar spinal block by posterior rotation of anulus fibrosus: case report. J Neurosurg 1973;39:642-47 CrossRef Medline

4. Schellinger D, Manz HJ, Vidic B, et al. Disk fragment migration. Radiology 1990;175:831-36 CrossRef Medline

5. Tarukado K, Tono O, Doi T. Ordinary disc herniation changing into posterior epidural migration of lumbar disc fragments confirmed by magnetic resonance imaging: a case report of a successful endoscopic treatment. Asian Spine J 2014;8:69-73 CrossRef Medline

6. Chen CY, Chuang YL, Yao MS, et al. Posterior epidural migration of a sequestrated lumbar disk fragment: MR imaging findings. AJNR Am J Neuroradiol 2006;27:1592-94 Medline

7. Tarukado K, Ikuta K, Fukutoku Y, et al. Spontaneous regression of posterior epidural migrated lumbar disc fragments: case series. Spine J 2015;15:e57-62 CrossRef Medline

8. Diehn FE, Maus TP, Morris JM, et al. Uncommon manifestations of intervertebral disk pathologic conditions. Radiographics 2016;36: 801-23 CrossRef Medline

9. Derincek A, Ozalay M, Sen O, et al. Posterior epidural mass: can a posteriorly migrated lumbar disc fragment mimic tumour, haematoma or abscess? Acta Orthop Belg 2009;75:423-27 Medline

10. Akhaddar A, El-Asri A, Boucetta M. Posterior epidural migration of a lumbar disc fragment: a series of 6 cases. J Neurosurg Spine 2011; 15:117-28 CrossRef Medline

11. Sengoz A, Kotil K, Tasdemiroglu E. Posterior epidural migration of herniated lumbar disc fragment. J Neurosurg Spine 2011;14:313-17 CrossRef Medline

12. Teufack SG, Singh H, Harrop J, et al. Dorsal epidural intervertebral disk herniation with atypical radiographic findings: case report and literature review. J Spinal Cord Med 2010;33:268-71 CrossRef Medline

13. Eksi MS, Yener U, Akakin A, et al. Posterior epidural disc herniation at L3-L4 mimicking a spinal tumor: a case report. J Neurosurg Sci 2010;54:71-76 Medline

14. Kim JS, Lee SH, Arbatti NJ. Dorsal extradural lumbar disc herniation causing cauda equina syndrome: a case report and review of literature. J Korean Neurosurg Soc 2010;47:217-20 CrossRef Medline

15. Carvi y Nievas MN, Hoellerhage HG. Unusual sequestered disc fragments simulating spinal tumors and other space-occupying lesions: clinical article. J Neurosurg Spine 2009;11:42-48 CrossRef Medline
16. El Asri AC, Naama O, Akhaddar A, et al. Posterior epidural migration of lumbar disk fragments: report of two cases and review of the literature. Surg Neurol 2008;70:668-71; discussion 671 CrossRef Medline

17. Lakshmanan P, Ahuja S, Lyons K, et al. Sequestrated lumbar intervertebral disc in the posterior epidural space: a report on two cases and review of the literature. Spine J 2006;6:583-86 CrossRef Medline

18. Tatli M, Güzel A, Ceviz A, et al. Posterior epidural migration of sequestered lumbar disc fragment causing cauda equina syndrome. Br J Neurosurg 2005;19:257-59 CrossRef Medline

19. Walsh AJ, Martin Z, McCormack D. Cauda equina syndrome secondary to posterior epidural migration of a lumbar disc fragment: a rare phenomenon. Eur J Orthop Surg Traumatol 2004;14:30-31 CrossRef

20. Kim JH, Kong MH, Lee SK, et al. A case of posterior epidural migration of an extruded lumbar disc fragment causing cauda equina syndrome. J Korean Neurosurg Soc 2004;35:442-44

21. Kuzeyli K, Cakir E, Usul H, et al. Posterior epidural migration of lumbar disc fragments: report of three cases. Spine (Phila $\mathrm{Pa} 1976$ ) 2003;28:E64-E67 CrossRef Medline

22. Şenel A, Cokluk C, Celik F. Posterior epidural migration of extruded lumbar disc mimicking epidural mass: case report. Turk Neurosurg 2003;13:115-17

23. Kim MS, Hur JW, Lee JW, et al. Posterior and lateral epidural migration of extruded lumbar disc fragments: case report. $J$ Korean Neurosurg Soc 2003;33:297-98

24. Dösoğlu M, Is M, Gezen F, et al. Posterior epidural migration of a lumbar disc fragment causing cauda equina syndrome: case report and review of the relevant literature. Eur Spine J 2001;10:348-51 CrossRef Medline

25. Eysel P, Herbsthofer B. Dorsal compression of the epidural cord due to free sequestral lumbar prolapse: diagnostic problems in magnetic resonance imaging and computed tomography. Arch Orthop Trauma Surg 2001;121:238-40 CrossRef Medline

26. Şen O, Aydin MV, Erdoğan B, et al. Cauda equina syndrome caused by posterior epidural migration of an extruded lumbar disc fragment. Turk Neurosurg 2001;11:108-10

27. Lisai P, Doria C, Crissantu L, et al. Posterior epidural migration of an extruded free fragment from a lumbar disc herniation. J Orthopaed Traumatol 2000;2:103-05 CrossRef

28. Huang TY, Lee KS, Tsai TH, et al. Posterior epidural migration of sequestrated lumbar disc fragments into the bilateral facet joints: case report. Neurosurgery 2011;69:E1148-E51 CrossRef Medline

29. Jennett WB. A study of 25 cases of compression of the cauda equina by prolapsed intervertebral discs. J Neurol Neurosurg Psychiatry 1956;19:109-16 CrossRef Medline

30. Shephard RH. Diagnosis and prognosis of cauda equina syndrome produced by protrusion of lumbar disk. BMJ 1959;2:1434-39 CrossRef Medline

31. Diehn FE. Imaging of spine infection. Radiol Clin North Am 2012;50: 777-98 CrossRef Medline

32. Braun P, Kazmi K, Nogués-Meléndez P, et al. MRI findings in spinal subdural and epidural hematomas. Eur J Radiol 2007;64:119-25 CrossRef Medline

33. Apostolaki E, Davies AM, Evans N, et al. MR imaging of lumbar facet joint synovial cysts. Eur Radiol 2000;10:615-23 CrossRef Medline 